\title{
Are Multiple Tumors of the Parotid Gland Uncommon or Underestimated?
}

\author{
ACHIM M. FRANZEN ${ }^{1}$, ANNEKATRIN COORDES ${ }^{2}$, CHRISTIANE KAUP FRANZEN $^{3}$ and THOMAS GUENZEL $^{4}$ \\ ${ }^{1}$ Department of Otorhinolaryngology, Head and Neck Surgery, Campus Ruppiner Kliniken, \\ Brandenburg Medical University - Theodor Fontane, Neuruppin, Germany; \\ ${ }^{2}$ Department of Otorhinolaryngology, Head and Neck Surgery, Campus Benjamin \\ Franklin, Charité-Universitätsmedizin Berlin, Berlin, Germany; \\ ${ }^{3}$ General Practice, Neuruppin, Germany; \\ ${ }^{4}$ Department of Otorhinolaryngology, Head and Neck Surgery, Borromaeus Hospital Leer, Leer, Germany
}

\begin{abstract}
Background/Aim: Parotid gland tumors are mostly solitary tumors of the salivary gland tissue. There is limited evidence about multifocal tumor growth of the parotid gland. Patients and Methods: We reviewed medical records of 796 consecutive parotidectomies in 758 patients over the last 40 years in our department, and investigated the incidence and histological type of synchronous and metachronous parotid tumors. Multifocal recurrent tumors and hybrid tumors were excluded. Results: We identified 93 (13\%) patients with multiple parotid lesions. Their mean age was 63 (range $=15-93$ ) years. Multiple parotid tumors were found unilaterally in 59\% and bilaterally in $41 \%$ of cases. The contralateral tumor was diagnosed synchronously in 13 of 38 (34\%) cases and in 25 of 38 (66\%) cases metachronously. The time separating the diagnoses of both contralateral tumors ranged between one and eleven years. The same histological type was found in $95 \%$ of the tumors, and $96 \%$ of the parotid tumors had lymphatic origin. Warthin tumors (65\%) were the most frequent histological type. Conclusion: Every sixth patient with a parotid tumor has multifocal tumor lesions. The majority of multifocal parotid tumors have a lymphoid element, while multifocal growth is uncommon in other histological types.
\end{abstract}

Parotid gland tumors are mostly solitary tumors of the salivary gland tissue. Multiple parotid tumors are occasionally reported, but the majority of these are single case reports or

Correspondence to: Dr. Thomas Guenzel, Department of Otorhinolaryngology, Head and Neck Surgery, Borromaeus Hospital Leer, Kirchstrasse 61-67, 26789 Leer, Germany. Tel: +49 491 65840, Fax: +49 491 65859, e-mail: info@hno-praxis-leer.de

Key Words: Parotid gland, parotid tumor, Warthin tumor, multifocal, parotidectomy. small case series. Therefore, we lack comprehensive knowledge about the incidence and clinical importance of multiple parotid tumors. Similarly, there are no established theories on their genesis and why certain histological types more commonly result in multiple tumors than others.

The aim of the present study was to examine the relevance of multifocal tumor growth in parotid gland tumors. Therefore, we evaluated the medical records of 796 consecutive parotidectomies over the last 40 years in our department.

\section{Patients and Methods}

We retrospectively analyzed medical records from 796 parotidectomies performed on 758 patients between 1975 and 2016. Surgery for a neoplastic lesion was performed in 703 of these patients, and for inflammation in 55 patients. In 116 out of 703 (16\%) patients a malignant tumor was found, while the remaining 587 patients were diagnosed with benign tumors. To highlight the relevance of multifocal tumor growth for differential diagnoses of the parotid gland, we included inflammatory pseudotumors and cysts, primary malignant lymphoma of the parotid gland and metastatic tumors. Multifocal recurrent tumors (pleomorphic adenomas, 4 cases) and hybrid tumors with biphasic differentiation were excluded.

We evaluated gender, age at the time of surgery, patient history and diagnostic data, histology, and extent of the parotidectomy. The preoperative diagnostic evaluation included B-scan ultrasonography in the last 20 years. Given the long observation period, palpation or sialography was performed only in 8 patients. Computed tomography and Magnetic Resonance Imaging examinations were performed in selected cases only. Preoperative cytology or histological examinations were not performed in the presented patients.

All patients with multiple parotid tumors underwent a subtotal or total parotidectomy with preservation of the facial nerve. The patients with bilateral tumors always underwent parotidectomy in two separate operations. In one patient with parotid metastases of a cutaneous squamous cell carcinoma (who presented with a facial palsy prior to surgery) the nerve function remained unchanged. 
All investigations and treatments are established clinical practices and were performed according to accepted clinical practices and in compliance with medical principles of the Declaration of Helsinki and German Federal Law. Informed consent was obtained from all patients prior to treatment. In this retrospective case series, formal ethical approval was not required.

\section{Results}

The study included 93 of 758 (13\%) patients with multifocal parotid tumors. In this group, 131 parotidectomies were performed. The majority of patients had noticed the presence of a parotid lump for 12 months (range=1-120 months). The tumor diameter of the largest tumor was on average $3 \mathrm{~cm}$ (range $=2-6 \mathrm{~cm}$ ), measured by ultrasonography. Further tumors were smaller. The mean patient age was 63 years (range $=15-93$ years). At the time of the initial diagnosis, five patients were $<50$ years, and 42 of 93 patients were $>70$ years. A total of 68 out of $93(73 \%)$ patients presenting multiple tumors were men.

In 55 of $93(59 \%)$ cases, multifocal tumors were located unilaterally, and in 38 of 93 (41\%) cases bilaterally (Table I). Unilateral multiple tumors occurred synchronously in 54 of 55 (98\%) patients. In one patient, a second Warthin tumor grew caudally to the primary surgery site one year after the initial surgery. In patients with bilateral tumors, we found multiple tumors in one or both parotid glands in 23 of 38 $(61 \%)$ cases. The contralateral tumor was diagnosed (by ultrasonography) synchronously in 13 of 38 (34\%) cases and in 25 of $38(66 \%)$ cases metachronously (Table II). The time between the diagnoses of both contralateral tumors ranged between one and eleven years. In two thirds of multifocal tumor cases within one gland (50 of 78 cases), tumors were located in the superficial part of the gland. In all 15 cases with single tumors of the second gland, the tumor was found in the superficial part of the parotid gland.

Unilateral additional tumors were diagnosed before surgical intervention in approximately one third of cases. In another third of cases, an additional tumor was noted during parotidectomy, and the remaining tumors were diagnosed by histological examination of the specimen. Table I represents the different histological types and localisation of the multifocal parotid tumors. In 88 of 93 cases (95\%), multifocal tumors of the parotid glands were diagnosed as having the same histological type. Most of them were Warthin tumors (65\%). Further benign tumors included inflammatory pseudotumors or cysts, pleomorphic adenoma and tuberculosis. Malignant tumors of the same histological type were found in 19 cases, most commonly represented metastases of squamous cell carcinoma and NonHodgkin lymphoma. Metastases of squamous cell carcinoma in the parotid gland, presenting as multifocal tumors, had a cutaneous squamous cell carcinoma as their primary tumor $(n=8)$ or an oropharyngeal carcinoma $(n=4)$. In another case we found a renal cell carcinoma metastasizing to both glands.
Five patients had multiple tumors of different histological types occurring synchronously, in all cases in combination with Warthin tumors. In four cases, a pleomorphic adenoma was found to be the other tumor, and in one case the metastasis of a squamous cell carcinoma of the outer acoustic channel.

\section{Discussion}

Tumors of the parotid gland may occur as multiple tumors with identical or different histology. Tumors can be unilateral or bilateral, synchronous or metachronous (1). The current evidence on incidence and significance of multiple tumors is mostly based on individual cases and small series (2). The biggest studies include 60 and 69 patients representing $3 \%$ and $5 \%$ of the performed parotidectomies, respectively $(3,4)$. Therefore, we evaluated the relevance of multifocal tumor growth in parotid gland tumors and investigated the medical records of 796 consecutive parotidectomies in 758 patients over the last 40 years. The present study is the biggest to date, including 93 patients with multiple parotid gland tumors. The proportion of multifocal tumor growth was 13\%. To emphasize the importance of multifocal tumor growth in the differential diagnosis of parotid gland tumors, we also included 5 inflammatory pseudotumors and one case of tuberculosis as well as 13 cases of parotid gland metastases. Excluding these types, the percentage of multifocal neoplasm was $12 \%$ (74 of 623 ). Reasons for the increased rate of multifocal tumors may be the comparably high proportion of Warthin tumors (241 of 703 cases), as well as the fact that we performed more extensive surgery on the parotid gland.

In the present study, unilateral multifocal tumors were found more frequently (59\%) than bilateral (41\%) tumors. The vast majority (95\%) of multiple tumors in our series were of identical histologic type (Table I) $(3,4)$. Among multifocal tumors with identical histology, Warthin tumors represent the majority of cases (5-7), and were much less than other histological entities (Table I) $(8,9)$. We detected Warthin tumors in $68 \%$ of cases. Most of them occurred bilaterally (58\%). The total frequency of multiple Warthin tumors among our patients was $26 \%$ and comparably high $(5,10)$. Our results support the findings that the risk of multiple Warthin tumors correlates with the amount of nicotine intake: all but three of our patients with multiple Warthin tumors were smokers $(6,10)$. Multifocal tumor growth was also more common in men and older patients, which may be due to the high proportion of Warthin tumors and metastases $(3,11)$.

Reports about multiple benign tumors of other histological types are rare and exist mainly as single case reports (12). Pleomorphic adenomas are the most common parotid gland tumors. However, they are rarely present as multifocal tumor growth. In these cases, they grow bilateral and occur 
Table I. Histological types and localisation of multifocal parotid tumors ( $n=93)$.

\begin{tabular}{|c|c|c|c|c|}
\hline Histological type & $\begin{array}{l}\text { Total multifocal } \\
\text { parotid tumors } \\
\quad(n=93)\end{array}$ & $\begin{array}{l}\text { Unilateral multifocal } \\
\text { parotid tumors } \\
\qquad(\mathrm{n}=55)\end{array}$ & $\begin{array}{l}\text { Bilateral multifocal } \\
\text { parotid tumors } \\
\quad(\mathrm{n}=38)\end{array}$ & $\begin{array}{l}\text { Total cases of the } \\
\text { histologic entity } \\
(\mathrm{n}=570)\end{array}$ \\
\hline \multicolumn{5}{|l|}{ Identical histology } \\
\hline Warthin tumor & 60 & 25 & 35 & 240 \\
\hline Pleomorphic Adenoma & 3 & 1 & 2 & 244 \\
\hline Inflammatory pseudotumors and cysts & 5 & 5 & 0 & 23 \\
\hline Tuberculosis & 1 & 1 & 0 & 2 \\
\hline Adenocarcinoma & 1 & 1 & 0 & 8 \\
\hline Non-Hodgkin-Lymphoma & 5 & 5 & 0 & 19 \\
\hline Metastasis of squamous cell carcinoma & 12 & 12 & 0 & 40 \\
\hline Metastases of renal cell carcinoma & 1 & 0 & 1 & 1 \\
\hline \multicolumn{5}{|l|}{ Different histology } \\
\hline Warthin tumor + Pleomorphic Adenoma & 4 & 4 & 0 & \\
\hline Warthin tumor + Metastasis of squamous cell carcinoma & 1 & 1 & 0 & \\
\hline
\end{tabular}

Table II. Histological types of metachronous multifocal tumors.

\begin{tabular}{lcc}
\hline Histological type & All tumors of involved histologic types $(\mathrm{n}=62)$ & Metachronous tumors $(\mathrm{n}=28)$ \\
\hline Warthin Tumor unilateral & 24 & 1 \\
Warthin Tumor bilateral & 35 & 24 \\
Pleomorphic Adenoma bilateral & 2 & 2 \\
Metastases of renal cell carcinoma & 1 & 1 \\
\hline
\end{tabular}

metachronously. In our series, only 3 of 245 cases with pleomorphic adenoma presented with multifocal tumor growth. However, two synchronous, well separated tumors in one parotid gland are a rare exception $(13,14)$. The majority of multiple pleomorphic adenomas are recurrent tumors (15) and were therefore excluded from the study.

The most common malignant tumor entity in our series were metastases of squamous cell carcinomas. Metastases of the parotid gland are relatively frequent in cutaneous squamous cell carcinoma of the head and neck (16). We also found four cases of metastatic oropharynx squamous cell carcinoma (17) and one case of a renal cell carcinoma metastasizing to both glands 6 and 12 years after the initial tumor diagnosis (18). One patient with two synchronous primary adenocarcinomas was an unusual finding. In literature, the most common primary malignant parotid tumor with multifocal tumor growth is acinic cell carcinoma $(19,20)$.

In the present study, multifocal tumors of different histological types were rare (5\%). In all five cases, a Warthin tumor was found synchronously unilateral, in combination with four cases of a pleomorphic adenoma and one case with metastatic squamous cell carcinoma. The current literature includes several individual case reports about the combination of two benign tumors, a malignant and a benign tumor, or malignant tumors of different histological types $(21,22)$. A combination of Warthin tumor and pleomorphic adenoma is the most common presentation $(3,11)$.

It is generally acknowledged that Warthin tumors develop from heterotopic glandular duct epithelium in intraparotid lymph nodes that were included in the gland prior to capsule development during embryogenesis, and subsequent late encapsulation entrapped those lymphatic tissues (23-25). The discussion over their pathogenesis remains inconclusive, as current genetic investigations support a 1950's hypothesis that the nature of Warthin tumors is not neoplastic and results from immunological interaction between epithelium and lymphoid stroma, resulting in hyperplasia of the lymphoid components, and non-clonal proliferation of its epithelial components, and that Warthin tumors should rather be classified as a tumor-like lesion and not as a benign tumor (26-29). Other parotid tumors that have a tendency to develop multiple lesions are also derived from lymphatic tissue (30). Most parotid gland lymph nodes are located in the superficial part of the parotoid gland and this may explain why multifocal tumors were mainly found superficially. 
In our 758 patients undergoing parotidectomies over the last 40 years, we found multiple tumors in approximately every sixth patient. The vast majority $(96 \%, 89$ of 93 cases) of multifocal parotid tumors were of lymphatic origin: Warthin tumors, parotid lymphoma, inflammatory pseudotumors and metastatic lesions (Table I). Today, the actual significance of multiple tumors is even higher because Warthin tumors have become by far the most important tumor entity among neoplasms of the parotid gland over the last two decades.

Multifocal parotid gland tumors were more likely to be synchronous (70\%) than metachronous (30\%). These findings are reflected in literature $(7,31)$. All metachronous tumors had identical histology and all but two cases were Warthin tumors. These results are similar to those reported in other series $(3,4)$.

Ipsilateral multiple tumors were identified preoperatively by clinical examination or imaging in just one third of cases - a surprising but previously documented phenomenon (3). Reasons for this may be the examiner's failure to investigate the possibility of multiple tumors, the small size of the additional tumor compared to the larger first tumor, and the misinterpretation of a second tumor as an intraglandular lymph node. In another one third of cases, an additional tumor was detected by intraoperative palpation of the tissue and confirmed by histology, while the remaining third was diagnosed by postoperative histopathology alone. Because fine-needle aspiration biopsy depends on ultrasonography, its use in the diagnosis of multiple tumors remains controversial. Fine needle aspiration cytology and intraoperative frozen section histopathology evaluation have been considered to avoid parotidectomy, but are not sensitive or specific enough, especially in particularly heterogenous tumors $(5,32,33)$.

Bilateral multiple tumors were detected by clinical examination or imaging and confirmed by histological examination in all cases. In most cases, tumor growth occurred metachronously. Whether a metachronous tumor of the second side was missed at the time of tumor diagnosis of the other side remains to be discussed.

Our patients underwent subtotal (meaning at least partial) resection of the deep glandular portion or total parotidectomy with facial nerve preservation. A more extended surgical approach may have been the reason why one third of multiple tumors in our series were diagnosed in the histopathological investigation. In less extended surgeries, these cases may have been erroneously diagnosed as recurrence during the follow-up examination. One patient with multiple Warthin tumors underwent revision surgery because a second Warthin Tumor grew caudally to the primary surgery site one year after the initial surgery. We interpret this situation as the manifestation of a secondary tumor, possibly in a periparotid lymph node.

Based on our results, the possibility of multiple tumors should be considered in the pre-operative work-up especially in examiner-dependent investigations such as ultrasound scanning. Even a small secondary tumor should be addressed and removed in the following operation. If fine-needle aspiration biopsy is part of the preoperative diagnostic procedure, biopsies should be taken from every tumor. According to our results patients with multiple Warthin tumors on one side will develop at least one additional Warthin tumor on the other side in two thirds of cases. Therefore, we recommend that patients with multiple Warthin tumors should be carefully followed-up including examination of the opposite parotid gland.

\section{Conclusion}

Every sixth patient with a parotid tumor has multifocal tumor lesions. The most common histological types have a lymphoid element, while multifocal growth is uncommon in other histological types. The possibility of multifocal tumors should be considered both during the preoperative diagnostic evaluation (e.g. ultrasonography) and intraoperatively during palpation of the remaining glandular tissue. Especially in cases when the preoperative histology shows lymphatic tissue origin, multifocal tumor growth should be taken into account before planning the definitive treatment. Extended surgery including the deep lobe of the gland should be performed when multifocal tumors are suspected. A careful postoperative follow-up including the contralateral parotid gland is recommended in cases of multifocal Warthin tumors.

\section{Conflicts of Interest}

All Authors declare that they have no competing financial and nonfinancial interests. All investigations and treatments were carried out according to accepted clinical practice and were compliant with the medical principles of the Declaration of Helsinki and German Federal Law.

\section{References}

1 Seifert $\mathrm{G}$ and Donath $\mathrm{K}$ : Multiple tumours of the salivary glands-terminology and nomenclature. Eur J Cancer B Oral Oncol 32B(1): 3-7, 1996.

2 Andrews L and Shah N: Multiple, synchronous, unilateral parotid adenomas: a case series. Br J Oral Maxillofac Surg 53(6): 526-528, 2015.

3 Ethunandan M, Pratt CA, Morrison A, Anand R, Macpherson DW and Wilson AW: Multiple synchronous and metachronous neoplasms of the parotid gland: the Chichester experience. Br J Oral Maxillofac Surg 44(5): 397-401, 2006.

4 Yu G-Y, Ma D-Q, Zhang Y, Peng X, Cai Z-G, Gao Y and Chen $\mathrm{Y}$ : Multiple primary tumours of the parotid gland. Int J Oral Maxillofac Surg 33(6): 531-534, 2004.

5 Ascani G, Pieramici T, Rubini C, Messi M and Balercia P: Synchronous bilateral Warthin's tumours of the parotid glands: a case report. Acta Otorhinolaryngol Ital 30(6): 310-312, 2010. 
6 Peter Klussmann J, Wittekindt C, Florian Preuss S, Al Attab A, Schroeder U and Guntinas-Lichius O: High risk for bilateral Warthin tumor in heavy smokers-review of 185 cases. Acta Otolaryngol 126(11): 1213-1217, 2006.

7 Hall JE, Statham MM, Sheridan RM and Wilson KM: Multifocal synchronous ipsilateral Warthin tumors: case report and review of the literature.Ear Nose Throat J 89(9): E1-3, 2010.

8 Huang Y-C, Wu C-T, Lin G, Chuang W-Y, Yeow K-M and Wan Y-L: Comparison of ultrasonographically guided fine-needle aspiration and core needle biopsy inthe diagnosis of parotid masses. J Clin Ultrasound 40(4): 189-194, 2012.

9 Curry JL, Petruzzelli GJ, McClatchey KD and Lingen MW: Synchronous benign and malignant salivary gland tumors in ipsilateral glands: a report of two cases and a review of literature.Head Neck 24(3): 301-306, 2002.

10 Teymoortash A, Krasnewicz Y and Werner JA: Clinical features of cystadenolymphoma (Warthin's tumor) of the parotid gland: a retrospective comparative study of 96 cases. Oral Oncol 42(6): 569-573, 2006.

11 Zeebregts CJ, Mastboom WJB, van Noort G and van Det RJ: Synchronous tumours of the unilateral parotid gland: rare or undetected? J Craniomaxillofac Surg 31(1): 62-66, 2003.

12 Hyde J, Takashima M, Dodson B and Said S: Bilateral multinodular oncocytomas of the parotid arising in a background of bilateral oncocytic nodular hyperplasia. Ear Nose Throat $\mathbf{J}$ 87(1): 51-54, 2008.

13 Silva SJ da, Costa Junior GT, Brant Filho AC, Faria PR and Loyola AM: Metachronous bilateral pleomorphic adenoma of the parotid gland. Oral Surg Oral Med Oral Pathol Oral Radiol Endod 101(3): 333-338, 2006.

14 Miliauskas JR and Hunt JL: Primary unilateral multifocal pleomorphic adenoma of the parotid gland: molecular assessment and literature review. Head Neck Pathol 2(4): 339342, 2008.

15 Laskawi R, Schott T and Schröder M: Recurrent pleomorphic adenomas of the parotid gland: clinical evaluation and long-term follow-up. Br J Oral Maxillofac Surg 36(1): 48-51, 1998.

16 Khurana VG, Mentis DH, O’Brien CJ, Hurst TL, Stevens GN and Packham NA: Parotid and neck metastases from cutaneous squamous cell carcinoma of the head and neck. Am J Surg 170(5): 446-450, 1995.

17 Olsen SM, Moore EJ, Koch CA, Kasperbauer JL and Olsen KD: Oral cavity and oropharynx squamous cell carcinoma with metastasis to the parotid lymph nodes. Oral Oncol 47(2): 142144, 2011

18 Lieder A, Schneider C, Lebentrau S, Günzel T and Franzen A: Diagnostic relevance of metastatic renal cell carcinoma in the head and neck: An evaluation of 671 cases. International Braz J Urol 43(2): 202-208, 2017.
19 Slater L: Bilateral multifocal parotid tumors: acinic cell carcinomas versus nodular oncocytic hyperplasia. J Oral Maxillofac Surg 71(4): 655, 2013.

20 Durand N, Mourrain-Langlois E, Leclair F and Malard O: Synchronous bilateral acinic cell carcinoma of the parotid: when a tumor reveals another one. Eur Ann Otorhinolaryngol Head Neck Dis 130(1): 22-25, 2013.

21 Guldfred L-A, Becker BC and Eiholm S: Multiple synchronous tumours of different histological type of the salivary glands. Ugeskr Laeger 170(18): 1571, 2008.

22 Stavrianos SD, McLean NR and Soames JV: Synchronous unilateral parotid neoplasms of different histological types. Eur J Surg Oncol 25(3): 331-332, 1999.

23 McKean ME, Lee K and McGregor IA: The distribution of lymph nodes in and around the parotid gland: an anatomical study. Br J Plast Surg 38(1): 1-5, 1985.

24 Albrecht $\mathrm{H}$ and Arzt L: Beitrag zur Frage der Gewebsverirrung. Frankfurter Zeitschrift fuer Pathol 4: 47, 1910.

25 Rosai J and Suster S: Warthin's tumors. Hum Pathol 32(3): 352, 2001.

26 Arida M, Barnes EL and Hunt JL: Molecular assessment of allelic loss in Warthin tumors. Mod Pathol 18(7): 964-968, 2005.

27 Teymoortash A and Werner JA: Tissue that has lost its track: Warthin's tumour. Virchows Arch 446(6): 585-588, 2005.

28 Thompson AS and Bryant HC: Histogenesis of papillary cystadenoma lymphomatosum (Warthin's tumor) of the parotid salivary gland. Am J Pathol 26(5): 807-849, 1950.

29 Honda K, Kashima K, Daa T, Yokoyama S and Nakayama I: Clonal analysis of the epithelial component of Warthin's tumor. Hum Pathol 31(11): 1377-1380, 2000.

30 Seethala RR, Thompson LDR, Gnepp DR, Barnes EL, Skalova A, Montone K, Kane S, Lewis JS Jr, Solomon LW, Simpson RH, Khan A and Prasad ML: Lymphadenoma of the salivary gland: clinicopathological and immunohistochemical analysis of 33 tumors. Mod Pathol 25(1): 26-35, 2012

31 Nascimento LA, Ferreira JAS, Pio RB, Takano GHS and Miziara HL: Synchronous bilateral warthin tumors: a case report. Int Arch Otorhinolaryngol 18(2): 217-220, 2014.

32 Alphs HH, Eisele DW and Westra WH: The role of fine needle aspiration in the evaluation of parotid masses. Curr Opin Otolaryngol Head Neck Surg 14(2): 62-66, 2006.

33 Olsen KD, Moore EJ and Lewis JE: Frozen section pathology for decision making in parotid surgery. JAMA Otolaryngol Head Neck Surg 139(12): 1275-1278, 2013.

Received July 12, 2017

Revised July 29, 2017

Accepted August 1, 2017 